\title{
ANÁLISE DO GERENCIAMENTO DA INOVAÇÃO: Estudo multicaso em supermercados de município da região noroeste do RS
}

\author{
Jocias Maier ZANATTA ${ }^{1}$
}

Daniel Knebel BAGGIO²

Mauro Alberto NUSKE ${ }^{3}$

\begin{abstract}
${ }^{1}$ Mestrando em Desenvolvimento na Universidade Regional do Noroeste do Rio Grande do Sul (UNIJUI), Especialista em Gestão Financeira, auditoria e controladoria, Bacharel em Administração. Professor do Curso de Bacharelado em Administração da Sociedade Educacional Três de Maio (SETREM) e da Faculdades Alterativas Santo Augusto (FAISA), Coordenador de Infraestrutura do Hospital São Vicente de Paulo. jociaszanatta@ @etrem.com.br

${ }^{2}$ Doutor de Contabilidade e Finanças UNIZAR. Professor do Programa de Pós-Graduação em Desenvolvimento UNIJUI (Mestrado em Desenvolvimento). baggiod@unijui.edu.br

${ }^{3}$ Mestre em Engenharia da Produção pela Universidade Federal de Santa Maria (UFSM), Especialista em Administração Financeira, Bacharel em Administração. Professor, Pesquisador e Procurador Institucional da Sociedade Educacional Três de Maio (SETREM). mauronuske@ setrem.com.br
\end{abstract}

Recebido em: 13/10/2015 - Aprovado em: 28/03/2016 - Disponibilizado em: 30/07/2016

\begin{abstract}
RESUMO
O setor supermercadista é de grande relevância para o Brasil, sendo responsável em 2012, por 5,4\% do produto interno bruto e $83,7 \%$ do abastecimento de alimentos no país (HONDA, 2012; ROCHA e QUINTÃO, 2012). A temática da inovação é fundamental para o desenvolvimento das organizações, tendo impacto direto na competitividade e sobrevivência das mesmas, no entanto, os cases de sucesso são predominantes em grandes corporações. Este estudo buscou definir o perfil de gerenciamento da inovação em organizações supermercadistas de micro, pequeno e médio porte no município de Três de Maio, na Região Noroeste do RS. O estudo multicaso teve como premissa a pesquisa com os gestores dos supermercados, utilizando-se da ferramenta de auto avaliação proposta por Tidd et al (2008) e o gráfico radar do Microsoft Excel®. Dentre os resultados, verifica-se que o supermercado com porte micro não gerencia a inovação, o de porte pequeno está em estágio inicial de inovação, tendo o perfil de gerenciamento focado em organização e relacionamento, e o de porte médio também encontra-se em estágio inicial de inovação, com o perfil de gerenciamento baseado em estratégia, organização e relacionamento.
\end{abstract}

Palavras-chave: Supermercado. Inovação. Gráfico radar.

\section{ABSTRACT}

The supermarket sector is of great importance to Brazil, accounting in 2012 for $5.4 \%$ of gross domestic product and $83.7 \%$ of the food supply in the country (HONDA, 2012; ROCHA and QUINTÃO, 2012). The theme of innovation is fundamental to the development of organizations, having a direct impact on the competitiveness and survival of them, however, success stories are prevalent in large corporations. This study sought to define the innovation management profile in supermarket organizations of micro, small and medium businesses in the city of Três de Maio, the RS Northwest Region. The multi-case study was premised on research with managers of supermarkets, using the selfassessment tool proposed by Tidd et al (2008) and the radar chart from Microsoft Excel®. Among the results, it appears that the micro-sized supermarket does not manage to innovation, small is in the early stages of innovation, with the management profile focused on organization and relationship, and the medium is also in early stage innovation with the management profile based on strategy, organization and relationship

Keyworks: Supermarket. Innovation. Graphic radar. 


\section{INTRODUÇÃO}

A temática da inovação acompanha e se desenvolve ao longo da história da civilização. A necessidade de inovar está presente em quase tudo o que conhecemos, a ideia do novo, do desconhecido, é algo que estimula os estudos, principalmente a partir dos anos 90, onde a tríplice hélice (governo, universidades e organizações) enfatizarem que a inovação é um diferencial estratégico (PAREDES; SANTANA; FELL, 2014).

Percebe-se no cotidiano das organizações, que a inovação é um desafio complexo, a velocidade das mudanças ocorre em tempo real, e a geração de inovações em produtos e serviços transforma-se em um dos principais elementos de competitividade, sendo preponderante para a sobrevivência das organizações

(BAUTZER,

2009;

CARRETEIRO, 2009)

O Manual de OSLO (2005) é importante diretriz para coleta e interpretação de dados sobre inovação, e define a inovação como sendo "a implementação de um produto (bem ou serviço) novo ou significativamente melhorado, ou um processo, ou um novo método de marketing, ou um novo método organizacional nas práticas de negócios, na organização do local de trabalho ou nas relações externas".

Muitas organizações trabalham pela busca da excelência em seus produtos ou serviços através da gestão da inovação, investindo em pesquisa e desenvolvimento e criando ambiente favorável a criatividade. Ao exemplificar estratégias de inovação, é imprescindível citar a empresa 3M do Brasil, fundada em 1946, com mais de 55.000 itens de produtos, com divisão de negócios organizada por mercado, onde trabalha com o conceito de inovação como a aplicação prática da criatividade, onde a criatividade é pensar em coisas novas, a invenção é mostrar que pode ser feito e a inovação é tornar comercializável e dar retorno a todos, além disso, trabalha com elevado número de patentes, projetos incrementais e radicais e grande parte das vendas advém de novos produtos, tudo isto, só é possível pelo investimento em pesquisa e desenvolvimento e cultura da inovação e liberdade para empreendedorismo dos colaboradores (SERAFIM, 2011).

Outro case de excelência em inovação é o da empresa de capital nacional Brasilata S.A. que atua no setor de embalagens de aço, setor considerado pulverizado e competitivo. O processo de inovação da empresa, iniciou com reestruturação administrativa, adoção de técnicas gerenciais e um canal de comunicação para recebimento de ideias dos colaboradores; as inovações não foram somente nos produtos, em 1991 a empresa introduziu a participação nos resultados, quatro anos antes da legislação, este modelo de gestão é a base dos seus processos de inovações em produtos e processos, trazendo 
a empresa os principais prêmios ligados a inovação (BARBIERI; ÁLVARES, 2013).

No ambiente supermercadista, o estudo de Zago et al (2007), procurou pesquisar sobre a cadeia de valor de redes associativistas, em pequenos e médios supermercados, tendo elucidado que, por meio da união em rede, obtiveram maiores ganhos organizacionais, agregando valor as atividades.

O setor supermercadista possui grande relevância na economia brasileira (ROCHA, QUINTÃO, 2012), e em 2012 foi responsável por $5,4 \%$ do PIB do país, tendo crescido 4,4 \% em relação a 2010, sendo ainda, responsável por $83,7 \%$ do abastecimento de alimentos, bebidas, itens de higiene, limpeza e beleza (HONDA, 2012).

Neste contexto, do grande número de estudos realizados, importância da temática para as organizações da indústria, comércio e serviços, e para o Brasil, surge a pergunta orientadora deste estudo: Qual o perfil de gerenciamento da inovação em organizações supermercadistas de micro, pequeno e médio porte no município de Três de Maio - RS?

\section{FUNDAMENTAÇÃO TEÓRICA}

\subsection{Estratégia}

No meio empresarial o conceito de estratégia popularizou-se a partir da década de
60, de forma associada ao planejamento estratégico. A partir deste momento, iniciouse efetivamente a prática de olhar para o futuro e definir objetivos para as organizações, em um contexto de mudanças, que exige reposicionamentos constantes na gestão das organizações (SAUSEN, 2012). Entende-se, que em se tratando de estratégia, existem numerosas definições e conceitos distintos, havendo consenso de que a utilização de estratégias é uma atividade de conteúdo e de processo variável, onde é possível aplicar vários modelos, que podem favorecer ou não o sucesso de uma administração (BETHLEM, 2001).

Porter (1989), ao analisar a indústria, mostra as cincos forças competitivas: a entrada de novos concorrentes, a ameaça ode substitutos, o poder de negociação dos compradores, o poder de negociação dos fornecedores e a rivalidade entre os concorrentes existentes; menciona ainda, estratégias genéricas para atingir um desempenho acima da média: liderança de custo, diferenciação e enfoque. Schumpeter (1982), ao analisar a competitividade observa que no sistema capitalista, a concorrência deve ser baseada no desenvolvimento de novos produtos, técnicas, fontes de recursos e formas organizacionais.

A perspectiva estratégica supõe as organizações em evolução, alcançando novos resultados como fruto de sua capacidade de adaptação ao meio e de inovação, sendo a 
decisão estratégica resultado de um processo social, técnico e político, parcialmente controlável, por suas características racionais e ilógicas ao mesmo tempo (MOTTA, 2001).

\subsection{Inovação Organizacional}

Quando abordado o assunto da inovação, vale ressaltar, a dificuldade em definir o significado desta terminologia, devido a sua complexidade e amplitude, quanto pelo desconhecimento da temática e da frequente interpretação utilizando-se do senso comum. O maior equivoco da redução da inovação ao senso comum, é igualar invenção e inovação, onde ambos são diferentes, sendo que, a invenção para tornar-se uma inovação, deve ser comercializável, e uma inovação não precisa necessariamente ser uma invenção.

O termo inovação é usualmente empregado em diferentes contextos, um deles, é o de sinônimo de invenção, o qual se refere diretamente ao processo criativo, pode também ser usado para descrever o processo da inovação, no sentido de mudança para a organização, e a terceira perspectiva refere-se a ideia, prática ou artefato material inventado ou visto como novo, independente da utilização pela organização, com ênfase no porque algo é novo, e descreve atributos e dimensões (MOREIRA; QUEIROZ, 2007).

A inovação, assim como a capacidade de mudança, acompanha a natureza empresarial desde a Idade Média, e com o tempo percebeu-se que, o conceito de inovação não está somente relacionado ao poder inventivo das pessoas, mas ao complexo processo de mecanismo de traduzir processos em vantagens competitivas (BAUTZER, 2009).

A vantagem competitiva se dá pela utilização de recursos estratégicos através de estratégia eficiente. A vantagem competitiva é medida pelo valor econômico superior que a estratégia cria em relação aos concorrentes (PORTER, 1989; BARNEY, 1991), e a sustentabilidade desta vantagem conquistada está associada aos recursos serem de difícil obtenção ou imitação (PETERAF, 1993).

O início da pesquisa acerca da temática da inovação foi com JoshephSchumpeter (1982) com a tese da inovação como destruição criativa, que investigou a influência na inovação no modo de agir das organizações no mercado e sua influência nos resultados. A abordagem da inovação como destruição criativa, sustenta que a concorrência no sistema capitalista deve estar centrada no desenvolvimento de novos produtos, de novas técnicas, busca por novas fontes de recursos e de novas formas e configurações

organizacionais (SCHUMPETER, 1992).

O Manual de OSLO (OCDE, 2005), elaborado pela Organização para Cooperação e Desenvolvimento Econômico, contribui para a elevação da competitividade das empresas brasileiras, e define a inovação 
como sendo "a implementação de um produto (bem ou serviço) novo ou significativamente melhorado, ou um processo, ou um novo método de marketing, ou um novo método organizacional nas práticas de negócios, na organização do local de trabalho ou nas relações externas".

O mesmo manual, ainda divide a inovação em quatro grandes áreas: produto, processo, marketing e organização. O termo produto abrange bens e serviços, e a inovação em produtos entende-se pela utilização de novos conhecimentos ou tecnologias ou novas combinações de utilização; a inovação em processos pode ter diversos objetivos, entre eles, redução de custos, melhoria na qualidade, aperfeiçoamento da distribuição (logística), e frequentemente, este tipo de inovação está relacionado a tecnologia; a inovação em marketing é direcionada para o relacionamento com o consumidor e o atendimento de suas necessidades, além da ampliação de mercado e ampliação de vendas; para finalizar, as inovações organizacionais consiste na implementação de novos métodos, para as rotinas e procedimentos de trabalho, vislumbrando a melhoria das rotinas, satisfação dos colaboradores e maior produtividade (OCDE, 2005).

Para Tidd et al (2008), quando se fala em inovação basicamente entende-se ela por mudança, que pode ocorrer em diversas formas, que descrê em quatro categorias: inovação de produto, mudança nos produtos ou serviços que uma empresa oferece; inovação de processo, mudanças na forma em que os produtos e serviços são criados e entregues; inovação de posição, mudança no contexto em que produtos e serviços são introduzidos; e por fim, inovação de paradigma, que consiste na mudança nos modelos mentais que orientam a empresa.

Uma inovação pode caracterizar-se pelo grau de novidade envolvido, desta forma, é possível subdividir a inovação em: incremental ou radical. Nesta perspectiva, a inovação incremental é resultado de melhorias menores, por exemplo atualizar o modelo de um carro, enquanto a inovação radical, caracteriza-se por mudanças radicais, que mudam conceitos, como por exemplo, um novo conceito de carro movido a eletricidade (TIDD et al, 2008).

O processo para a busca da inovação é complexo, e depende da estratégia adotada pela organização, onde a gestão da organização compreende o processo de aprendizagem organizacional, onde uma invenção difere-se de inovação, ou seja, para caracterizar-se por inovação tem de ser comercializável. Para o Presidente da FINEL Glauco Arbix (2010), uma inovação pode nascer de uma invenção, no entanto, a inovação precisa resultar num produto, processo ou serviço no mercado. 
Figura 1 - Processo para a busca da inovação

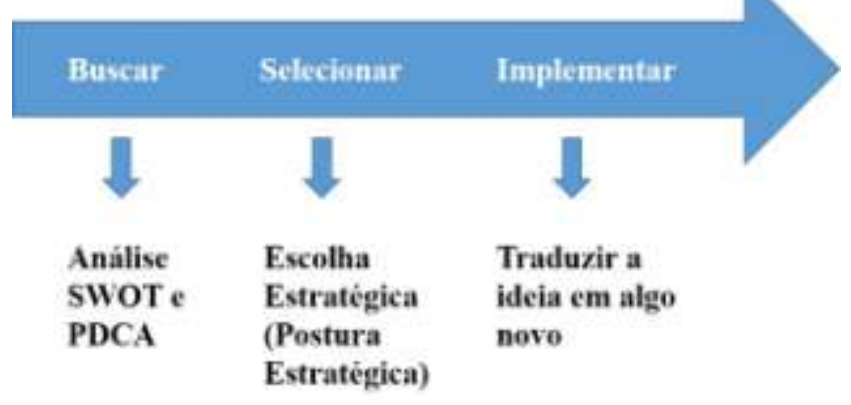

Fonte: Adaptado de Tidd et al (2008, p. 88)

As organizações tem de buscar compreender o ambiente no qual atuam, além de suas próprias competências e limitações, de modo a desenvolver estratégias eficientes e eficazes, neste sentido torna-se imprescindível o estudo ferramentas úteis para o diagnóstico organizacional e mercadológico (CERIBELI; PRADO; MERLO, 2010). A busca da vantagem competitiva exige análise detalhada do ambiente em busca de condições que possam determinar ameaças ou emergir oportunidades (HAMPTON, 1992).

Nas organizações, a gestão da inovação não deve limitar-se pela ótica de um processo gerencial essencial, é preciso também, ter clareza a cerca de seus limites, objetivos e contexto competitivo e estratégico (SILVA; BAGNO; SALERNO, 2014). A gestão da inovação é componente fundamental para tornar a organização mais competitiva, onde existem uma gama diversificada de estratégias de inovação.

A estratégia a ser adotada é reflexo do porte, maturidade e recursos disponíveis da organização, que por sua vez, pode optar pela estratégia mais simples, a cópia, ou a mais complexa e onerosa, a pesquisa e desenvolvimento. Sendo que, dentro da escala de estratégias de inovação, quando maior a proximidade da pesquisa e desenvolvimento, maior será o diferencial competitivo no mercado globalizado.

Figura 2 -Estratégias de inovação

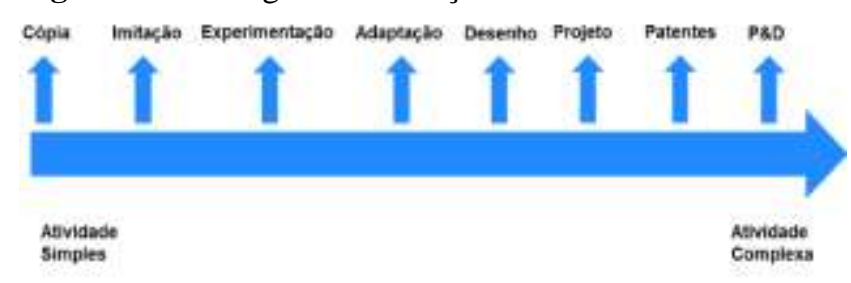

Fonte: Adaptado de Figueiredo (p. 35)

\subsection{Inovação em Serviços}

Na década de 90, se aplicava conceitos de manufatura na inovação em serviços, o que nesse escopo, restringia a relação de inovação e serviços a apenas o acompanhamento da difusão de inovações tecnológicas (BARRAS, 1986). O crescimento do setor terciário impulsionou a discussão sobre a inovação em serviços, onde as organizações que atuam neste segmento se diferenciam dos demais, pela proximidade com o cliente e o fato da inovação ser muitas vezes intangível, onde a inovação se dá através de novas formas de interação com clientes e mudanças de comportamento.

Sundbo e Gallouj (2000) afirmam, que o processo de inovação em serviços é um processo interativo, onde o prestador de serviços mantém ligações internas e externas 
intrínsecas na própria execução dos serviços que conduzem à inovação.

A inovação em serviços pode ser categorizada em três abordagens principais: a abordagem tecnicista, que restringe a inovação em serviços ao uso de tecnologias; a abordagem baseada em serviço, que busca descobrir as particularidades da natureza e organização da inovação em serviços; e a abordagem integradora, que estabelece uma estrutura conceitual comum através da convergência entre produtos e serviços (GALLOUJ; SAVONA, 2009).

\section{METODOLOGIA}

Com o intuito de verificar o perfil de gerenciamento da inovação em organizações supermercadistas, realizou-se uma pesquisa descritiva, com abordagem de triangulação entre os métodos quantitativo e qualitativo, e as estratégias de pesquisa utilizadas foram a técnica de estudo multicasco, pesquisa bibliográfica, em artigos científicos e documental. A pesquisa descritiva buscou identificar, expor e descrever fatos ou fenômenos de determinada realidade. Dessa forma, foram escolhidos como objeto de estudo três supermercados de Três de Maio, na região Noroeste do Estado do Rio Grande do Sul, classificados pelo seu porte como micro, pequeno e médio, de acordo com a metodologia do SEBRAE.
A pesquisa compreendeu o período de abril a maio de dois mil e quinze, e para a coleta e análise de dados com os gestores das empresas, foi utilizada a ferramenta de auto avaliação proposta por Tidd et al (2008), que dá subsídios para verificar o padrão de comportamento que descreve como a organização gerencia a questão da inovação, através das dimensões da estratégia, processos, organização, relacionamentos e aprendizagem. Para a visualização dos resultados foi utilizado o gráfico radar do Microsoft Excel ${ }^{\circledR}$, utilizando uma escala de 1 a 7 , sendo 1 (=definitivamente falso) e 7 (= muito verdadeiro).

\section{APRESENTAÇÃO E ANÁliSE DOS RESULTADOS}

\subsection{Objeto do Estudo}

Os supermercados são espaços onde grande parte da população circula e destina regularmente seus recursos monetários, suprimento uma demanda de abastecimento de gêneros alimentícios. Silveira e Lepsch (1997, p. 6) definem o supermercado como "um varejo generalista que revende ao consumidor final ampla variedade de produtos, dispostos de forma departamental, no sistema de autosserviço". Di Primo (1999), complementa o conceito de supermercado caracterizando-o pela ampla utilização de autosserviço, onde predomina, no mínimo, 
uma seção de mercearia contendo gêneros alimentícios.

Em consulta ao site do Banco Nacional do Desenvolvimento Econômico e Social (BNDES), circular $\quad N^{\circ} \quad 11 \backslash 2010$, observa-se que a classificação de porte das empresas, aplicável a todos os setores da economia, se dá através da receita operacional bruta anual. O BNDES entende que este indicador é resultado das receitas auferidas pela empresa no ano-calendário, compreendendo: o produto da venda de bens e serviços nas operações de conta própria, o preço dos serviços prestados e o resultado nas operações em conta alheia.

\begin{tabular}{|c|c|}
\hline Classificação & Receita operacional bruta anual \\
\hline Microempresa & Menor ou igual a $\mathrm{R} \$ 2,4$ milhões \\
\hline Pequena empresa & $\begin{array}{l}\text { Maior que } \mathrm{R} \$ 2,4 \text { milhões e menor ou igual a } \mathrm{R} \$ 16 \\
\text { milhões }\end{array}$ \\
\hline Média empresa & $\begin{array}{l}\text { Maior que R } \$ 16 \text { milhões e menor ou igual a R } \$ 90 \\
\text { milhões }\end{array}$ \\
\hline Média-grande empresa & $\begin{array}{l}\text { Maior que } \mathrm{R} \$ 90 \text { milhões e menor ou igual a } \mathrm{R} \$ 300 \\
\text { milhões }\end{array}$ \\
\hline Grande empresa & Maior que $\mathrm{R} \$ 300$ milhões \\
\hline
\end{tabular}

Fonte: BNDES (2010)

Outra forma de classificar o porte das empresas é pelo número de empregados, o Serviço de Apoio às Micro e Pequenas Empresas - SEBRAE utiliza esta metodologia, e define o porte das empresas de comércio e serviços da seguinte maneira: Micro, até 9 empregados; Pequena, de 20 a 49 empregados; Média, 50 a 99 empregados; e Grande, mais de 100 empregados.

Para a elaboração do estudo foi optado pela classificação proposta pelo SEBRAE, tendo a escolha das empresas sido amparada pelo número total de empregados, com a aplicação da pesquisa em três supermercados, distribuídos entre micro, pequeno e médio porte.

\subsection{Análise dos Resultados}

A partir da coleta de dados, analisouse os mesmos, levando-se em conta a particularidade de cada supermercado, bem como o ambiente em que está inserido e a forma de organização.

O supermercado com porte micro, até nove empregados, de modo geral, obteve os resultados mais pessimistas, o que demonstra que por ser um pequeno negócio, o conceito de inovação não está claro e difundido na organização. No entanto, observa-se que a dimensão relacionamentos e aprendizagem obtiveram pontuação intermediárias, ambas com nota 3 , isto deve-se a proximidade com o cliente final e a utilização da inovação através da tentativa e erro. Este tipo de empreendimento tem o apoio do SEBRAE através de consultorias de gestão, e possui características peculiares, como: atendimento em horário flexível, proximidade com clientes, preços elevados e geralmente predomina o trabalho em família. São os considerados mercados de vizinhança, pois possuem como foco clientes de uma certa região do município, como uma bairro ou uma vila. 
A figura 3 representa de forma gráfica os resultados com este empreendimento.

Figura 3 - Gráfico radar supermercado micro

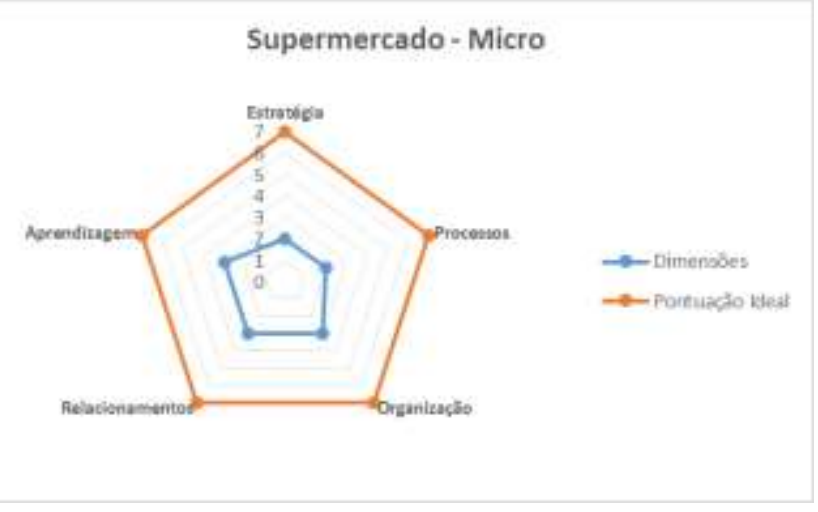

Fonte: Dados da pesquisa

Os resultados referentes ao supermercado de pequeno porte, de vinte a quarenta e nove empregados, mostra que estão em estágio inicial em relação a inovação, no entanto, já demonstram pontuação intermediária em estratégia, nota 3 , e pontuação satisfatória em organização e relacionamentos, ambas com nota 4. Esta organização demonstra estar inserida em ambiente com maior competitividade que os de porte micro, por ter estrutura maior, mais colaboradores, e atingir público de maior abrangência e de menor fidelização, tendo que utilizar-se de estratégias de inovação relacionadas a competitividade de custos.

A figura 4 demonstra de forma gráfica os resultados com este empreendimento.
Figura 4 - Gráfico radar supermercado pequeno Supermercado-Pequeno

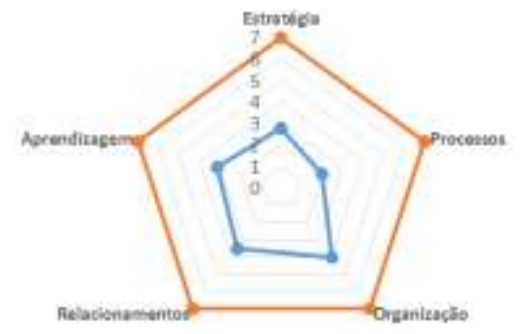

$\rightarrow-$ Dimernuacto kleat

Fonte: Dados da pesquisa

O supermercado de médio porte, de cinquenta a noventa e nove empregados, foi o que apresentou melhores resultados, relativos as dimensões pesquisadas, tendo nota 4 , nas dimensões estratégia, organização e relacionamentos. A empresa apresenta estrutura organizacional definida, estratégia com enfoque no desenvolvimento do negócio e relacionamento estreito com fornecedores.

Porém, verifica-se na figura 5 que as dimensões com menor pontuação são processos e aprendizagem, o que pode ser atribuído à inserção em um município com uma pequena população, com concorrência não muito representativa, não motivando seus gestores para a busca de um aprimoramento contínua em relação à aprendizagem, seguindo padrões tradicionais na condução de seus processos. 
Figura 5 - Gráfico radar supermercado médio Supermercado - Médio

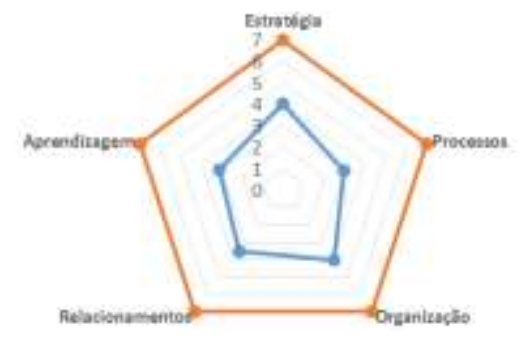

Fonte: Dados da pesquisa

\section{CONCLUSÃO}

O presente estudo possibilitou vivenciar a realidade dos supermercados quanto a temática da inovação, e percebe-se, a dificuldade encontrada para o estudo e gerenciamento da inovação por parte dos supermercados de micro, pequeno e médio porte pesquisados.

Os dados elucidados com a pesquisa, mostram que nenhum dos três supermercados pesquisados, independentemente de seu porte, apresentou maturidade em relação ao gerenciamento da inovação, e encontram-se distantes dos cases de sucesso apresentados na introdução.

O menor supermercado pesquisado, com porte classificado como micro, não apresentou gerenciamento da inovação, evidenciado pelo fraco desempenho no que tange à processos e estratégia, não sendo possível identificar seu perfil. No entanto, apresentou importantes características inerentes a sua condição de micro empresa, com predominância em relacionamentos com os clientes e aprendizagem através da tentativa e erro, assim como organização, dada à sua estrutura reduzida e atenção diferenciada, focada e integral de seus proprietários. $\mathrm{Na}$ aplicação do questionário ficou evidenciado a necessidade de auxílio na gestão do negócio e dependência de consultoria, como a oportunizada pelo SEBRAE.

O perfil de gerenciamento da inovação no supermercado de pequeno porte está orientado pelas dimensões de organização e relacionamentos, devido a melhor percepção da estrutura organizacional e ampliação do relacionamento as demais partes interessadas do negócio. Porém, da mesma forma que ficou evidenciado no mercado de porte micro, inovações relacionadas à processos e estratégia são pouco visíveis e detectáveis.

O supermercado de médio porte, é o que está em estágio inicial do gerenciamento da inovação, tendo o perfil do gerenciamento da inovação focado nas dimensões de estratégia, organização e relacionamentos. Em relação a organização anterior, além da organização e relacionamentos, tem a inovação inserida na perspectiva estratégica, onde tem clara orientação para o futuro, principalmente pela adoção de planejamento estratégico, utilização de ferramentas gerenciais e vivência de benchmarking. Como oportunidade de melhoria, inovações em processos são necessárias, na busca da dinamização e otimização dos resultados. 
O estudo demonstra a necessidade de as organizações pesquisadas aprofundarem os seus conhecimentos sobre a inovação, e difundi-lo nas dimensões apresentadas na pesquisa. A pesquisa teve como limitação a percepção do gestor das organizações que responderam a pesquisa, cabendo a estudos futuros discutir a temática sobre outros olhares.

\section{REFERÊNCIAS BIBLIOGRÁFICAS}

ARBIX, Glauco. Estratégias de inovação para o desenvolvimento. Tempo Social, Revista de Sociologia da USP, v. 22, n. 2, p. 167$185,2010$.

BARRAS, R.. Towards a theory of innovation in services. Research Policy. v. 15, p. 161173, 1986.

BAUTZER, Deise. Inovação: repensando as organizações. São Paulo: Atlas, 2009.

BARNEY, J. Firm resources and sustained competitive advantage. Journal of Management, Thousand Oaks, v. 17, n. 1, p. 99-120, Mar., 1991.

\section{BETHLEM, Agricola. Estratégia}

empresarial: conceitos, processo e administração estratégica. 3. ed. São Paulo: Atlas, 2001.

\section{CARRETEIRO, Ronald Pinto. Inovação}

Tecnológica: como garantir a modernidade do negócio. Rio de Janeiro, LTC, 2009.

CERIBELI, H. B.; PRADO, L. S.; MERLO, E. M. Uma aplicação conjunta das análises Swot/Pest para avaliação de estratégias competitivas no varejo. Revista IberoAmericana de Estratégia, v. 9, n. 1, p. 77$101,2010$.
DI PRIMIO, F. A história dos supermercados gaúchos. Porto Alegre: Agas, 1999.

Gallouj, F., Savona, M. (2009). Innovation in services: a review of the debate and the research agenda.

JournalofEvolutionaryEconomics, 19(2), 149172.

HAMPTON, David R. Administração contemporânea: teoria, prática e casos. 3 . Ed. São Paulo: Pearson Makron Books, 1992.

HONDA, S. Rota de crescimento.

Superhiper, 38 (430), 2012.

Banco Nacional de Desenvolvimento Econômico e Social. Circular no 34 Normas regulamentadoras do produto BNDES Automático. Disponível em: http://www.bndes.gov.br/SiteBNDES/bndes/b ndes_pt/Institucional/Apoio_Financeiro/porte. html Acesso em 18/03/2015

MOREIRA, Daniel Augusto; QUEIROZ, Ana Carolina S. (Coords.) Inovação organizacional e tecnológica. São Paulo: Thomson Learning, 2007.

MOTTA, Paulo Roberto. Gestão contemporânea: a ciência e a arte de ser dirigente. 12. ed. Rio de Janeiro: Record, 2001 .

PAREDES, B. J. B.; SANTANA, G. A.; FELL, A. F. A. Um estudo de aplicação do radar da inovação: o grau de inovação organizacional em uma empresa de pequeno porte do setor metal-mecânico. NAVUS Revista de Gestão e Tecnologia, v. 4, n. 1, p. 76-88, 2014.

\section{PETERAF, M. A. The cornerstones of} competitive advantage: a resource-based view. Strategic Management Journal, USA, v. 14, n. 3, p. 179-191, 1993.

Porter, Michael E. Vantagem competitiva: criando e sustentando um desempenho superior. Rio de Janeiro: Campus, 1989. 
SAUSEN, Jorge Oneide. Gestão estratégica, competitividade e desenvolvimento: um olhar a partir das suas inter-relações. In:

DieterRugard. (Org.). Desenvolvimento sob múltiplos olhares. Ijuí: Unijuí, 2012.

SCHREIBER, D.; THEIS, V. A análise da relevância da inovação no processo de concepção estratégica: estudo de caso em uma empresa de componentes para calçados. BASE - Revista de Administração e Contabilidade da UNISINOS, v. 11, n. 4, p. 292-303, 2014.

SCHUMPETER, J.A. 1982. Teoria do desenvolvimento econômico: uma investigação sobre lucros, capital, crédito, juro e o ciclo econômico. São Paulo, Abril Cultural, $169 \mathrm{p}$.

SERAFIM, Luiz Eduardo. Inovação viabiliza Excelência na Execução de Estratégia e Planejamento: Case 3M. In: Encontro do Conhecimento em Administração ENCOAD (CRA-SP), 2011, São Paulo.

Serviço de Apoio às Micro e Pequenas Empresas de Santa Catarina. Critérios de Classificação de Empresas: EI - ME - EPP. Disponível em: http://www.sebraesc.com.br/leis/default.asp?vcdtexto $=4154$ Acesso em 18/03/2015.

SILVA, Debora Oliveira da; BAGNO, Raoni Barros; SALERNO, Mario Sergio. Modelos para a gestão da inovação: revisão e análise da literatura. Production, v. 24, n. 2, p. 477-490, 2014.

SILVEIRA, J. A.; LEPSCH, S. L. Alterações recentes na economia do setor supermercadista brasileiro. Revista de Administração, São Paulo, v. 32, n. 2, p. 20-24, 1997.

ORGANIZAÇÃO PARA COOPERAÇÃO E DESENVOLVIMENTO ECONÔMICO (OCDE). 2005. Manual de Oslo: Diretrizes para Coleta e Interpretação de Dados sobre Inovação. $3^{\text {a }}$ ed., Rio de Janeiro, FINEP. Disponível em: http://www.mct.gov.br/index.php/content/vie w/4639.html Acesso em: 16/02/2015.

ROCHA, I. C. T.; QUINTÃO, R. T.

Utilização do processo de Gerenciamento por Categorias no setor supermercadista: uma comparação entre empresas de diferentes portes. Amazônia, Organizações e

Sustentabilidade, v. 1, n. 2, p. 19-31, 2012.

SUNDBO, J.; GALLOUJ, F. Innovation as a loosely coupled system in services.

International Journal of Services Technology and Management. v. 1, n. 1, p. 15-36, 2000.

TIDD, Joe.; BESSANT, John.; PAVITT, Keith. Gestão da Inovação. 3. ed. Porto Alegre, Bookman, 2008.

ZAGO, Camila Avozani; CAMFIELD, Cláudio Eduardo Ramos; POLACINSKI, Édio; GODOY, Leoni Pentiado;

WITTMANN, Milton Luiz. Redes associativas como inovação organizacional: estudo de caso de uma rede supermercadista. RAI - Revista de Administração e Inovação, v. 4, n. 1, p. 57-70, 2007. 